\title{
AUGMENTED, ASSESSED, ADDRESSED: REFRAMING THE CURRICULA FOR FIRST YEAR STEM STUDENTS
}

\author{
Dr. Mike Hobbs ${ }^{1}$, Dr. Debbie Holley ${ }^{2}$ \\ ${ }^{1}$ Department of Computing and Technology, Anglia Ruskin University (UK) \\ ${ }^{2}$ Bournemouth University (UK)
}

\begin{abstract}
There is a particular challenge with engaging technically motivated STEM students with 'softer skill' development, despite clear evidence from employers that these skills are highly desirable. In the UK, Higher Education Institutes response has been to require undergraduate courses to contain an element of Personal Development Planning (PDP)[1]. Our paper directly addresses the issue of trying to engage students from Computer and Gaming courses with their PDP. Previous experiences of teaching these cohorts traditionally report low attendance and poor completion rates, impacting on first year/second year progression. This study reports on work reframing the curricula for this essential aspect of the student learning experience, by offering the students realistic and authentic tasks by 'flipping' the classroom. This requires them to work in small groups, selecting, designing and then creating an augmented reality artefact using 'Aurasma'[2], a free software tool for developing augmented reality objects. We note that the co-design process of curriculum development has enhanced student engagement; student completion rates have significantly increased, and class attendance improved.
\end{abstract}

Keywords: STEM, Augmented Reality, Student Engagement, PDP, BYOD

\section{INTRODUCTION}

The 'STEM paradox' [3] outlines key differences expectation between student perspectives of what a technical degree should contain and what employers in the science and technical sectors are seeking. Both academics and employers agree that scientific understanding and technical ability are important, but students typically fail to fully appreciate the requirement to gain and demonstrate the soft skills that employers find essential [4]. STEM degrees often include soft skills but the majority of marks (and hence degree classification) depend on demonstrating technical ability. This imperative to gain what are perceived as rare and useful skills overshadows soft skills, even when (as we discovered in this study) the students were aware of their importance for employability. The House of Lords Select Committee Report into Higher Education in Science, Technology, Engineering and Maths (STEM) subjects 2012 flagged up concerns with the mismatch between the Governmental aspirations to 'retool for a high-tech future' [5] and advising that 'jobs of the future will increasingly require people with the capabilities that a STEM qualification provides'. The following year, the education and skills survey in 2013 [6] identified that this was a significant problem within the wider issue of low numbers of STEM students. The problem is intensified by industry bodies such as the IET, BCS and Skillset who encourage University courses to provide soft skills but rightly require a rigorous focus on technical skills. Other studies demonstrate the gap between what companies need and the provision currently offered by higher education institutions, with communication skills and independent problem solving being identified as a significant problem. [3][4]

Personal Development Planning (PDP) is a common element in UK Higher Education as Universities are required to provide a transcript to record student learning and achievement, as well as a process by which they can monitor, build and reflect on their on-going development [6][7]. This initiative has its origins in the UK Government Quality Assurance Agency (QAA) report 2009 [1] setting out a framework to quality enhance learning for an increasing diverse student body. Key aspects of this are for students to become more independent, adopt a pro-active approach to their study, extra-curricular pursuits and career planning. 


\subsection{Context of this study}

This paper reports on the second iteration of the 'Augmented Reality (AR) for learning skills project' at Anglia Ruskin University. The first stages of this work were reported in Hobbs and Holley [9]; and showed that students attendance patterns were transformed, they engaged inside and outside the classroom, and work submission rose from $66 \%$ to $82 \%$. The project has been extended from sixty students in three classes based in a single course to 130 students in five classes in two different courses.

The scope of work has been extended by implementing suggestions on the curriculum from students and using the work created from the first iteration as examples to guide students. We have noted that the use of previous examples, in particular the blogs, which outlined the developmental process from the student point of view, give the current students a boost in understanding the technology and they have set more challenging goals for themselves. The basic AR applications now incorporate design, testing and peer evaluation and has been extended to include the creation of a 'treasure hunt' application game. The paper concludes with suggested guidelines for others that may be interested in replicating some aspects of this work into their own teaching/learning contexts.

The background to the work is the poor end of year Course Reviews for the core year 1 Computing and Gaming module; these identified issues of poor engagement with the module, seen in low pass rates for assessment and lack of attendance. Upon further analysis, it became apparent that the PDP component of the module was where the issue lay, and the tension of delivering a STEM curriculum with a high discipline based content, with the requirement to deliver 'softer skills was problematic. This has traditionally been delivered through a series of one hour tutor led classes/lectures on topics such as: Self-Evaluation Exercise, Note Taking, Group Work, Presentations, Library and referencing Skills, Report Writing, Keeping a Log Book, Time Management, Submitting Work, Plagiarism and the creation of the PDP portfolio. Clearly, a redesign was needed, and a more creative approach considered [10][11].

\section{AUGMENTED REALITY (AR) - ENCOURAGING A TEAM-BASED APPROACH}

The teaching team approached the pedagogic experts in the Department of Education, to consider best how to resolve the conundrum identified above. Their solution was to suggest supporting student team working through the framework of collaborative learning (CL), framed by Vygotskys' theories of learning as a social and constructivist process [12]. Collaborative learning draws upon notions of students working together towards a common goal, and is underpinned through Vygotsky and his zone of proximal development (ZPD). A systematic literature review of $\mathrm{CL}$, undertaken by Shawkey et al. [13] shows our technology of choice, Augmented Reality, as one of several successful instruments, a view supported by Lin et. al. [13].

Since the introduction of AR (1990s) [15] augmented reality systems have been used in higher education [16] and STEM subjects such as maths [17] and physics [18] Yuen et al [19] suggested five directions for AR in education - books, gaming, discovery based learning, object modelling and skills training. The benefits are essentially a 'real world', authentic experience. Carmigniani and Furht [20] extensively review the educational contexts of AR by providing a taxonomy of systems and applications, and focus on the outcomes of interactive, context aware and content rich experiences for the users. For the purposes of our re-conceptualisation of the curricula for PDP, a significant sub-set of simple AR application creation tools are now freely available for those with limited technical ability to become AR creators. These newer, user friendly technologies [21] combined with the rise of smartphone usage [22] now enables students to access educational AR applications via their own device. This study is located within the user-generated content of SMART devices, as our students are creating their own 'team' artefacts using the Aurasma AR 'App' [2]; and drawing upon the work of [23] classification of games using LAYAR.

\subsection{Selection of Aurasma}

Augmented Reality links media (image/video/audio) to a scene viewed through the camera of a mobile device. Key features of the image or object are recorded by the application, which treats these like a URL or QR code to trigger linked media. The media can be presented on its own, but more typically it is laid over the scene in the camera image viewer to produce a composite, or augmented, view of reality. AR is identified as a key emergent technology in the NMC Horizon Higher Education Preview 
[24] and the pedagogic context of its use as an education tool is the focus of research by assessment expert Bloxham [25]. Wu et al. [26] provide a good overview of the educational uses of AR up to 2013, since then increasing, awareness, availability of devices and application development platforms have extended the range of educational applications [27]. Objects can be used as triggers for artifacts in museums, or provide instruction for using technical equipment, or to enhance illustrations and text in books. The interaction is focused on the current learning context and provides a good motivator for context focus of engagement and communication [28]. Our view is that while there are advantages to locating media triggers in the real world, students will gain more benefit from the 'experiential learning' opportunity to develop their own materials

Although utilizing sophisticated technology, the tools and development environment are accessible to non-experts via applications such as Blippar [29] and Aurasma [2], so as well as integrating AR resources into the curriculum it is possible for students and staff to create their own artifacts in a constructive learning context. Of the available technology the Aursama app was chosen for the following reasons.

1. Has a publicly available free version,

2. Available on mobile devices (i-Phone and Android,)

3. Development can be entirely on mobile device.

4. Designed for user created content.

Systems designed for user created content have the advantage that anyone can build a simple AR application, but also the disadvantage that the tools available are simple and limited. However, in our study the key aim is not to produce a high quality artifact but to create a high quality learning experience.

Having a free version that students can download and use themselves releases the feeling of ownership and responsibility [28]. This is particularly important to support the 'flipped' teaching concept where students have to take responsibility for their learning. Being able to complete the entire development process on their own devices enables students to be more flexible as to how, when and where they complete the tasks [30].

\section{METHODS}

This is an empirical study, and set within the qualitative tradition. Writing within the educational tradition, our approach has its emphasis on the particular and individual, the principle concern of which is with understanding 'the way in which individuals create, modify and interpret the world in which they find themselves' [31, p6]; thus we would position our work within the subjective approach to social science research/ and on the Idiographic dimension suggested by Burrell and Morgan 1979 (cited in Cohen et al [31]). The students, set the coursework briefing (see below) form self - selecting groups are tasked with selecting, planning and designing their own AR aura, around a loose concept of a 'treasure hunt', falling within the gaming genre of 'location based games' using cellular phones [ 32]. The study is observational in nature, as we note what the groups are 'doing' in terms of creativity and progress, but are facilitators rather than teachers, and we would very much see our remit in this work as moving from the "sage on the stage to the guide at the side' [33], and the flipped class approach [34] very much enables this role transformation.

Student brief: Students were asked to form groups of $3 / 5$ and think of a group name and logo that can be used as an Aurasma aura trigger. To given them a clear idea of what was required they were shown examples of auras created by the previous cohort of students. They were encouraged to plan, script and story board their interpretation of 'treasure hunt' style game. They selected locations as triggers with auras providing questions, clues or information. Weekly sessions were used for feedback, discussion and introducing the supporting materials on the student Virtual Learning Environment (VLE). Additional support was offered through email, discussion boards and comments posted on blog sites. Groups were asked to record progress on a group blog and to summarise their work in a short presentation to the class.

\subsection{Sampling}

Our evaluation of the project is based on qualitative (student questionnaire) and quantitative (student completion rate for PDP element) course indicators. We also selected three 'vignettes' drawn from the different student groups. These cases illustrate the different contexts within which the students 
selected to locate their AR projects. Two tutors ran classes based on the same material for 5 student groups (with between 19 and 29 in each group). Tutor 1 rand two Computer Gaming groups and Tutor 2 ran one Computer Science group and two Computer Gaming Groups. We selected one case study from tutor 1 (Case A) and two from tutor 2 (case B Gaming and case C Computing) for analysis.

Vignette $1 \mathrm{~A}$ home-based 'Hunt the word' (Computer Gaming team, Tutor 1)

Vignette 2 'Offsite' Treasure Hunt (Computing Science team, Tutor 2)

Vignette 3 University Locations Treasure Hunt (Computer Gaming team, Tutor 2)

\section{FINDINGS}

\subsection{Vignette 1: 'Hunt the Word'}

NERDS WITH

Team Name: 'Nerds with Attitude' 3 members (all males)

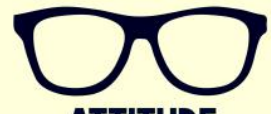

Brief description of project:

The students created a set of triggers, each one was linked to a letter of the alphabet, and the trigger images hidden round their student house. The students got their housemates to search for the letters, and when all had been located, the letters formed the word 'UNITY' which is the name of the game development system they used. The triggers all had a festive theme - Father Christmas, snowmen, etc. The students, although clearly friends, used 'Trello' to communicate; a visual and virtual pin-board [35]. Within this system they allocated roles, planned and communicated about the project, and set up a list of tasks. The students created cards on Trello, with different categories, and assigned members to task. They used the VLE blog as a final repository of ideas. Their presentation was short and succinct, and well received by the audience of their peers.

Extract of learning from their report:

"The first thing we decided to do was to find a way to communicate between the group in case any of us were unable to meet up..."

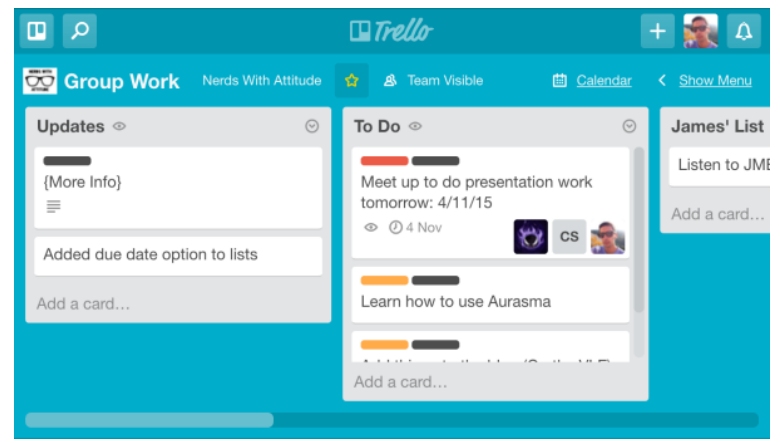

\subsection{Vignette 2: 'Locational Treasure Hunt'}

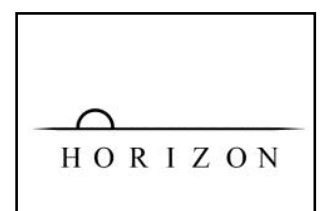

Team Name: 'Horizon' 4 members (all male)

For the treasure hunt aspect of the project, the students first created a riddle based hunt, then they changed ideas to having a password hidden behind a trigger. People on the treasure hunt could confirm they had been on the treasure hunt by handing in the series of passwords. There were 3 geographically spaced locations, starting with Compass House where the Department of Computing are located; moving to a nearby shopping centre, finally to the Crown Court. They swopped their auras with another group for user testing. Their presentation was sophisticated and polished, and they used the PowerPoint to talk through the stages of their work.

Extract of learning from their report:

"the importance of teamwork cannot be stressed enough, teamwork is the most fundamental aspect ..if we had not worked as a team we could have failed..." 


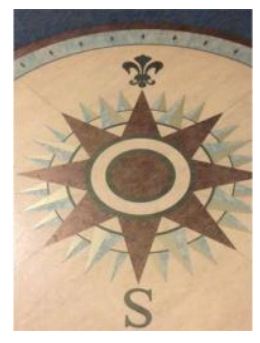

If you want to find out more you find Directions on the Floor, and just for that little matter, it's a Symbol for a letter!

\title{
4.3 Vignette 3: 'University Locations Treasure Hunt'
}

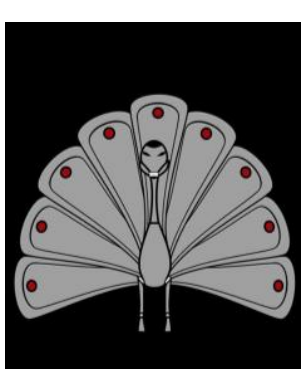

\author{
Team Name: The Fighting Peacocks 3 members (all male)
}

This group planned to make a treasure hunt that would be useful to University students for navigating round the Cambridge campus. Their logo was very creative and carefully thought through - when the user activated the aura, the peacock produced green beams that are targeted towards the user, the team noted this was in a 'star wars style'. Their final project included audio voiceover, which gave the user the clue for the next location. They also used QR codes so that people could also more easily find the exact trigger on their posters. The whole map comprised six key University locations.

Extract of learning from their report:

"tested another groups game, the results were very positive"

[note from tutor they developed a test grid for evaluation which they found very useful]

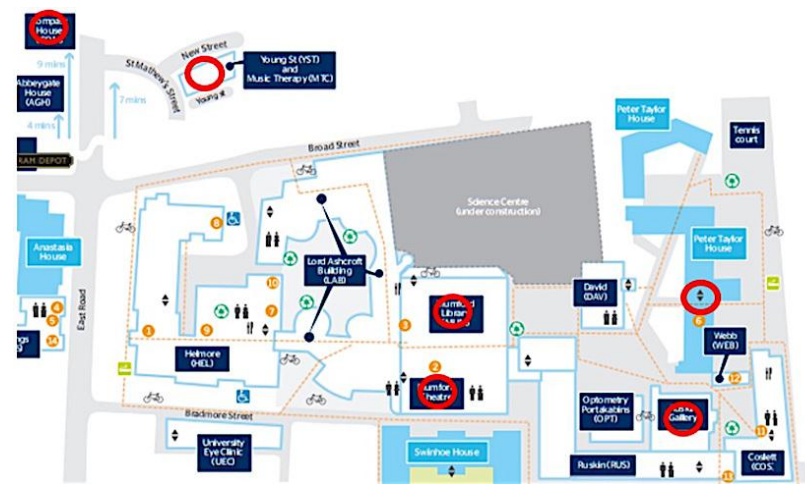

\section{DISCUSSION}

From the three vignettes it is clear that all of the teams engaged with the assessment brief, that they each interpreted the brief in very different contexts, and that each team worked successfully to create their own meaningful version of a 'Treasure Hunt'. All teams presented their findings, tested ideas with other users, and all of this within their first 12 weeks of University study. The classes were far better attended, compared with the previous year, with tutors reporting students coming along with a clear agenda about what they would like covered in the session, based on progress to date, although this did make some classes rather complicated to manage, with different groups at different stages of development. The tutors had already populated the VLE with key materials for each session, but were able to add weekly additional resource or commentaries that directly addressed the students concerns and interests.

Vignette $A$ and $C$, both undertaken by gaming students, have certain nuances that identify the students as embryonic gamers, although they may not yet see this in themselves. The ' $A$ ' team, with the Christmas theme and visualisations and sequence development and user testing are, indeed 
unconsciously absorbing their early engagement with the skills needed for this work. Similarly, "C" by drawing upon the Stars Wars analogy, are locating and positioning their work within the gaming 'genre'. Vignette B, from Computer Scientists, with their 'passwords' and levels of complexity, and demonstrating skills that have been introduced to them on a different module.

Course evaluation 'free text' comments show the impact of the redesigned curricula:

"Through lack of confidence I am/was finding it difficult to present...however, the group presentations through PDP has made me somewhat more comfortable with presentations"

"Learning about Teamwork and Organising meetings"

"Group work was a really good point and it helped improve my group working ability"

"Work completed without realising it!"

\section{CONCLUSIONS}

This is, of course, a small scale and localised study, and we are unable to generalise or make any 'grand claims'. However, our 'augmented, assessed and addressed' study has made a significant difference to 130 year one STEM students; they have made a much more positive and engaged start to their studies; they can identify useful additional skills the 'Treasure Hunt' exercise has facilitated such as group working, user testing, creativity and this has resulted in the students reporting enhanced confidence in their 'softer skills' development. For others considering the revision of their own curricula, the focus on the metaphor of a treasure hunt (or other familiar genre) and a focus on the offering of an excellent learning experience, rather than on developing an excellent technical solution/object seems to be the key to this transformational initiative. The students have the freedom to fail the actual task, yet, as long as they engage in the process and activities, they will have a successful outcome, and this fits well Vygotskys work relating to the zone of proximal development [36].

The initial study [9] was aimed at a homogenous set of students closely controlled by a single tutor, in this extension we have demonstrated that the concept is valid for mixed groups of students and for delivery by tutors who are new to the technology and educational process. We have also continued the improved level of completion by students (initial figures show $10 \%$ improvement over the base case) for this larger group.

\subsection{Future work}

This work is the second iteration of the 'AR mini project' to support PDP [9] and built on the previous work by using the Treasure Hunt theme to enable students to demonstrate more sophisticated design and creation skills. The requirement to increase the complexity of the task, and to make it more interesting, was based on feedback from students as part of the curriculum co-design process. Future work will seek to increase the degree to which students set their own assessment targets and the nature of the evidence required. Group structure was reinforced as students had to work within their groups and between groups to facilitate testing. We feel that the need to make their work usable for others students was a driver for better artefacts and more cohesive group work. Future work will gather evidence and look more closely at the factors involved in this process.

\section{REFERENCES}

[1] QAA (2009). Personal development planning: guidance for institutional policy and practice in higher education, The Quality Assurance Agency for Higher Education.

http://www.qaa.ac.uk/en/Publications/Documents/Personal-development-planning-guidance-forinstitutional-policy-and-practice-in-higher-education.pdf

[2] Aursasma (2015). Aurasma website, HP software, (2015). http://www.aurasma.com

[3] Harris, M. (2014). STEM paradox, is there really a shortage of STEM graduates in the workplace? Physics World, October 2014.

[4] UKCES (2014). The Labour Market Story: Skills for the Future, briefing paper 2014, UK Commission for Employment and Skills. 
https://www.gov.uk/government/uploads/system/uploads/attachment_data/file/344441/The_Lab our_Market_Story-_Skills_for_the_Future.pdf.

[5] House of Lords (2012). House of Lords Select Committee Report Science, Technology, Engineering and Maths (STEM) subjects (2012)

http://www.publications. parliament.uk/pa/ld201213/ldselect/ldsctech/37/37.pdf.

[6] CBI/Pearson (2013). Changing the pace - Education and Skills Survey. http://www.cbi.org.uk/media/2119176/education_and_skills_survey_2013.pdf.

[7] Houghton, W., Maddocks, A.(2005). Personal Development Planning for Engineering Students, Higher Education Academy, Engineering Subject Centre.

[8] QAA (2013). Recognizing achievement beyond the curriculum. http://www.qaa.ac.uk/assuringstandards-and-quality/skills-for-employability

[9] Hobbs, M., Holley, D. (2015) Using Augmented Reality to Engage STEM students with an authentic curriculum. $2^{\text {nd }}$ International Conference on e-Learning e-Education and Online Training, Sept 16th, 2015.

[10] Holley, D., Hobbs, M., Howlett, P. and Sawyerr, W.: The chaotic science lab': supporting trainee Science teachers a cross-departmental project. Anglia Ruskin University Networks, 16, pp.51--58 (2013) http://hdl.handle.net/10540/303566.

[11] Brown, E., Hobbs, M., and Gordon, M. (2008). A Virtual World Environment for Group Work, International Journal of Web-Based Learning and Teaching Technologies, 3(1): 1-12.

[12] Vygotsky, L.S. (1978). Mind in Society. The development of higher psychological processes (Cole, M., Ed.). Cambridge MA: Harvard University Press (Original work published 1930).

[13] Shawky, D., Said, T., Badawi, A., Hozayin, R. (2014) Affordances of computer-supported collaborative learning platforms: A systematic review, Interactive Collaborative Learning 2014 International Conference pp.633,651. doi:10.1109/ICL.2014.7017846.

[14] Lin, T, Duh, H., Li, N., Wang, H., Tsai, C. (2013). An investigation of learners' collaborative knowledge construction performances and behavior patterns in an augmented reality simulation system, Computers \& Education, Volume 68, October 2013, Pages 314-321, ISSN 0360-1315, http://dx.doi.org/10.1016/j.compedu.2013.05.011.

[15] Azuma, R. T. (1997). A survey of augmented reality. Presence-Teleoperators and Virtual Environments, 6 (4), 355 - 385.

[16] Liarokapis, F. and Anderson, E.F. (2010). Using augmented reality as a medium to assist teaching in higher education. Proc. of the 31st Annual Conference of the European Association for Computer Graphics (Eurographics 2010), volume Education Program : 9-16.

[17] Kaufmann, H., \& Schmalstieg, D.:Mathematics and geometry education with collaborative augmented reality.Computers \& Graphics, 27(3), 339-345 (2003)

[18] Ibáñez, María Blanca, et al.: Experimenting with electromagnetism using augmented reality: Impact on flow student experience and educational effectiveness. Computers \& Education71: 1$13(2014)$

[19] Yuen, S., Yaoyuneyong, G., and Johnson, E. (2011). Augmented reality: An overview and five directions for AR in education. Journal of Educational Technology Development and Exchange4.1: 119-140.

[20] Carmigniani, J., \& Furht, B. (2011) Augmented reality: an overview. In Handbook of augmented reality (pp. 3-46). Springer New York.

[21] EdTechReview (2015). Review on Augmented Reality [Online] http://edtechreview.in/trendsinsights/insights/1503-teaching-with-augmented-reality-it-s-here.

[22] Chen, B., Seilhamer, R., Bennett, L., Bauer, S. (2015). Students' Mobile Learning Practes in Higher Education: A Multi-Year Study. [Online] http://er.educause.edu/articles/2015/6/studentsmobile-learning-practices-in-higher-education-a-multiyear-study.

[23] Farjana Z. Eishita and Kevin G. Stanley. 2010. THEEMPA: simple AR games using layar. InProceedings of the International Academic Conference on the Future of Game Design and 
Technology (Futureplay '10). ACM, New York, NY, USA, 219-222.

DOI=http://dx.doi.org/10.1145/1920778.1920811

[24] NMC 2014, Horizon Report, 2014 Higher Education Preview, NMC. [online] Available at $<$ http://www.nmc.org/pdf/2014-horizon-he-preview.pdf>

[25] Bloxham, J., 2013. Pedagogical arguments for Augmented Reality as an educational tool. JISC, RSC blog. [online] Available at <http://jiscrsc.jiscinvolve.org/wp/2013/05/augmented-realityeducation/>

[26] Wu, H., Wen-Yu Lee, S., Chang, H. and Liang, J., 2013. Current status, opportunities and challenges of augmented reality in education. Computers \& Education, Vol. 62, pp. 41-49.

[27] Coimbra, T., Cardoso, T., Mateus, A. (2015) Augmented Reality: An Enhancer for Higher Education Students in Math's Learning?, Procedia Computer Science, Volume 67, 2015, Pages 332-339, http://dx.doi.org/10.1016/j.procs.2015.09.277.

[28] Martín-Gutiérrez, J., Fabiani, P., Benesova, W., Meneses, M., and Mora, C. 2015. Augmented reality to promote collaborative and autonomous learning in higher education. Comput. Hum. Behav. 51, PB (October 2015), 752-761. DOI=http://dx.doi.org/10.1016/j.chb.2014.11.093

[29] Blippar (2015). Blippar for Education. [Online] https://blippar.com/en/learn-more/blippar-foreducation/

[30] HEA (2015). Bring Your Own Device, HEA Frameworks \&Toolkits. [Online] https://www.heacademy.ac.uk/enhancement/starter-tools/bring-your-own-device-byod

[31] Cohen, L, Manion, L, and Morrisson, K (2011) Research Methods in Education (eds) 7th edition Abingdon and New York: Routledge

[32] Rashid, O., Mullins, I, Coulton, P and Edward, R (2006). Extending Cyberspace: location based games using cellular phones Computers in Education, Vol. 4, No1.

[33] King, A., (1993). From Sage on the Stage to Guide on the Side, College Teaching, Vol.41, No.1.

[34] Educause (2012. 7 Things you should know about flipped Teaching, Educause Learning Initiative. [Online] http://www.educause.edu/library/resources/7-things-you-should-know-aboutflipped-classroom.

[35] Trello (2015). Trello website. [Online] http://www.trello.com.

[36] Lee, C.D. and Smagorinsky, P. (2000) Vygotskian perspectives on literacy research: Constructing meaning through collaborative inquiry. Cambridge, England: Cambridge University Press. 